\title{
Epidemiology of pediatric skin diseases in the mid-western anatolian region of Turkey
}

\author{
Seval Dogruk Kacar, $M D^{a}$, Pinar Ozuguz, $M D^{a}$, Serap Polat, $M D^{a}$, \\ Vildan Manav, $M D^{a}$, Aysegul Bukulmez, $M D^{a}$, and Semsettin Karaca, $M D^{b}$
}

\begin{abstract}
Background: The field of pediatric dermatology has gained importance with the increment of pediatric patients and the discrepancy of their skin diseases with the adult versions. Weaimed to describe frequency and distribution of pediatric skin diseases, and the diagnostic procedures and treatments prescribed.

Methods: Cross-sectional epidemiological study. We collected data about diagnostic patterns, diagnostic methods and treatment modalities in pediatric dermatology outpatient clinic visits over 18 months.

Results: Infectious diseases (27.9\%) and among them viral warts (17.5\%) were the most prevalent diagnoses, followed by acne-acneiform diseases $(19.9 \%)$ and allergic diseases (14.5\%). Among the diagnostic tests histopathology was required in $5.2 \%$, usually to diagnose inflammatory and tumoral lesions. Topical treatments $(49.3 \%)$ were followed by systemic treatments (32.4\%) in majority of cases.

Conclusions: Viral warts were among the most common dermatoses, and preventive measures for HPV transmission should become important part of public health efforts in children.

Key words: pediatric skin disease, epidemiology, viral warts, diagnostic tests.
\end{abstract}

http:/ /dx.doi.org/10.5546/aap.2014.eng.421

\section{INTRODUCTION}

Skin diseases are common in children as well as in adults. Besides certain diseases are almost always observed in childhood, others may display age specific findings.

The field of pediatric dermatology (PD) has gained importance with the increment of pediatric patients and the discrepancy of skin diseases with the adult versions. Epidemiologic studies worldwide in the field of PD are limited. Geographical, environmental and socioeconomical factors may affect the frequency of diseases in pediatric population.

Data of pediatric cases among outpatient visits is not well described yet although there are studies estimating frequency of diseases at various pediatric age groups. We aimed to determine the distribution of diseases between various age groups, frequency of diagnostic procedures performed and the treatment modalities commonly used including immunosuppressive drugs.

We consider this information could be useful to take proper measures for prevention of diseases and handle the distribution of the public health resources.

\section{MATERIAL AND METHODS Study population}

This study was designed as a cross-sectional epidemiological study, retrospectively analyzing all consecutive pediatric admissions to Afyon Kocatepe University PD outpatient clinic over 18 months from September 2011 to February 2013. Permissions were obtained from the department and the study was conducted according to the Declaration of Helsinki guidelines. Afyonkarahisar is a small city located in midwestern Anatolia, with a population of 701.572 of which 355.073 $(50.61 \%)$ people live in city center, the remaining, inhabit in rural area. ${ }^{1}$

Our PD outpatient clinic examines and records patients less than 18 years old, who admits by himself/with parents or refers from a pediatrician, general physician or other clinics since September 2011.

Demographic data, diagnosis, diagnostic methods and treatment modalities of patients' are routinely recorded and we retrospectively collected the data from the medical records.

The pediatric population is evaluated in 4 age groups, as: infantile period (0-1), preschool age (2-5), school age (6-11) and adolescent period (12-17). 


\section{Diagnosis and diagnostic methods}

The diagnostic evaluation is recorded under ten main headings based mainly on etiopathogenesis. Diagnosis under headings are included in Table 1. All the diagnoses were made by dermatologists, based on clinical findings and diagnostic tests when required. The diagnostic tests including patch testing, microscopic, microbiological and histopathological examinations are noted as well.

\section{Treatment modalities}

Treatment methods were recorded in 4 groups based on the primary treatment modality preferred as simple topical treatment, systemic treatment, phototherapy, and other minor invasive methods including cryosurgery, cauterization, intralesional steroid injection, iontophoresis, and laser applications. Immunosupressive medication were additionally noted.

TABLE 1. The main diagnostic headings and diagnoses under headings ( $n$ total $=1984)$

\begin{tabular}{|c|c|c|c|}
\hline Acne and follicular diseases (395) & Papulosquamous diseases (86) & Allergic skin diseases (288) & Others (159) \\
\hline acne vulgaris (381) & guttate psoriasis (32) & atopic dermatitis (141) & generalized pruritus (76) \\
\hline infantile acne (5) & pityriasis rosea (18) & urticaria/ angioedema (71) & localized \\
\hline hidradenitis suppurativa (4) & chronic plaque psoriasis (16) & insect bite (68) & rhydrosis (19) \\
\hline milaria (4) & pityriasis rubra pilaris (6) & erythema multiforme (4) & ia pigmentosa / \\
\hline steroid acne (1) & lichen planus (3) & drug eruptions (3) & $s(7)$ \\
\hline & lichen simplex chronicus (2) & acute generalized erythematous & Behcet's disease (6) \\
\hline Eczemas (218) & lichen niditus (2) & pustulosis (1) & derma (7) \\
\hline t / allergic contact & pustular psoriasis (2) & & clerosis (2) \\
\hline titis (107) & asis lichenoides & Hair and nail diseases (120) & is vulva (5) \\
\hline pityriasis alba (34) & chronica (1) & alopecia areata $(33)$ & \\
\hline seborrheic dermatitis (29) & pityriasis lichenoides et & telogen effluvium (19) & itis (5) \\
\hline nummular dermatitis (8) & varioliformis acuta (2) & constitutional hirsutismus (18) & tus ani (3) \\
\hline photocontact dermatitis (9) & lichen striatus (2) & tractional alopecia (4) & iloma annulare (2) \\
\hline diaper dermatitis (10) & & hypertrichosis (4) & posttraumatic bullae (2) \\
\hline cheilitis (6) & skin & cicatricial alopecia (1) & sun burn (2) \\
\hline xerotic eczema (5) & tumors (88) & dystrophic nail (36) & striae distancea (2) \\
\hline pityriasis amiantecea (4) & junctional/compound nevi (31) & ingrown toe nail (4) & erythema nodosum (1) \\
\hline dyshidrotic eczema (3) & mongol spot (1) & onycholysis (1) & gA bullous \\
\hline ashy dermatosis (2) & verrucous epidermal nevus (2) & & de \\
\hline juvenile plantar dermatitis (1) & $\begin{array}{l}\text { nevus sebaceous }(4) \\
\text { milium (7) }\end{array}$ & $\begin{array}{l}\text { Disorders of pigmentation (56) } \\
\text { vitiligo (35) }\end{array}$ & ema annulare \\
\hline Infectious diseases (553) & Becker nevus (1) & postinflamm & oides \\
\hline arts (347) & lymphangioma (1) & pigmentation (17) & (1) \\
\hline molluscum contagiosum (34) & nevus lipomatosis superficialis (1) & cafe au lait macule (1) & (2) \\
\hline tinea capitis (22) & infantile hemangioma (3) & $\operatorname{mia}(1)$ & lein \\
\hline tinea corporis/pedis (60) & congenital melanocytic nevus (3) & pe & (1) \\
\hline herpes infections (19) & skin tag (2), ephelides (2) & hyperpigmentation (1) & $n$ \\
\hline folliculitis / furunculosis (16) & pilonidal sinus (2) & matory & ) \\
\hline tigo (9) & epidermal cyst (2) & hypopigmentation (1) & \\
\hline $\begin{array}{l}\text { scabies (9) } \\
\text { candidiasis (3) }\end{array}$ & $\begin{array}{l}\text { pyogenic granuloma (4) } \\
\text { keloid (9) }\end{array}$ & Genodermatosis (21) & 1) urpuric \\
\hline pityriasis versicolor (7) & angiokeratoma corporis & is vulgaris (6) & $\mathrm{a}(1)$ \\
\hline zona zoster (7) & diffusum (1) & icthyosis (4) & \\
\hline varicella (3) & spider angioma (3) & osis pilaris (2) & xanthagranuloma (1) \\
\hline acute paronychia (2) & ort wine stain (1) & fibromatosis (2) & pernio (1) \\
\hline cellulitis (5) & capillary venous malformation (1) & ectodermal displasia (2) & lingual frenulum (1) \\
\hline viral exanthemas (2) & spitz nevus (1) & is sclerosis (1) & orphic light \\
\hline pediculosis (1) & lipoma (1) & idermolysis bullosa (2) & eruption (1) \\
\hline tinea unguim (3) & nevus depigmentosus (1) & Vogt-Koyanagi-Harada & Lipschutz ulcer (1) \\
\hline balanitis (1) & dermoid cyst (1) & $\mathrm{s}$ & decubitus ulcer (1) \\
\hline infected dental sinus (1) & pilomatricoma (1) & Kenau & hot water burn (2) \\
\hline carbuncle (1) & & & \\
\hline otti-Cros & lippel-Treunay syndrome & & \\
\hline
\end{tabular}

* Numbers in paranthesis show the number of patients. 


\section{RESULTS}

\section{Age and sex distribution}

Among 2789 admissions to the PD outpatient clinic, 805 were repetitive either as control or recurrent treatment courses as cryosurgery or phototherapy. Of the 1984 patients enrolled to the study, the mean age was $10.87 \pm 5.11$.

\section{Frequency and pattern of skin diseases}

The most common diseases according to age groups are summarized in Table 2 and the top 15 dermatoses among all age groups are summarized in Table 3.

\section{Frequency of diagnostic tests}

Standart direct microscopy with potassium hydroxide was used in 229 of cases $(11.54 \%)$ of which 146 were positive. Fungal culture was less frequently preferred as in only 13 cases, with 2 positive results. Dermoscopy was performed in 72 cases $(3.63 \%)$, usually to diagnose benign skin tumors and hair diseases. Laboratory investigations were required in $232(11.69 \%)$ patients. Patch testing was applied in $12(0.60 \%)$ patients and only 3 of them revealed positive results with nickel, thiomersol and wool alcohol. On the other hand histopathology was required in $103(5.2 \%)$ patients, and the diagnosis of the patients who required histopathological examination are summarized in Table 4.

\section{Preferred treatment modalities}

Among the treatment modalities, topical treatments were given to $978(49.29 \%)$ of patients, followed by systemic treatment $643(32,41 \%)$ which more often consisted of antihistaminics and antibiotics. Immunosuppressive drugs including systemic steroids (38), methotrexate (2), cyclosporine (4) were given in $44(2,22 \%)$ of patients with diagnosis of psoriasis (4), urticaria (23), severe allergic/eczematous reactions (9) and alopecia areata (8). Phototherapy in the form of narrow-band UVB treatment was given in 27 $(1.36 \%)$ cases with the indications summarized in Table 5. Cryosurgery, cauterization and intralesional steroid injection were prefered in $207(10.43 \%), 2(0.10 \%)$ and $3(0.15 \%)$ cases, respectively. Of the 207 patients treated with cryotherapy, 204 had cutaneous warts. Eight $(0.40 \%)$ patients with localized hyperhydrosis

TABLE 3. The top 15 diseases in pediatric age group in our clinic

\begin{tabular}{lc}
\hline Skin diseases & n (\%) \\
\hline Acne vulgaris & $381(19.20 \%)$ \\
Viral warts & $347(17.49 \%)$ \\
Atopic dermatitis & $141(7.11 \%)$ \\
Irritant contact dermatitis & $102(5.14 \%)$ \\
Generalized pruritus & $76(3.83 \%)$ \\
Urticaria/angioedema & $71(3.58 \%)$ \\
Insect bite & $68(3.28 \%)$ \\
Tinea corporis/pedis/inguinalis & $60(3.02 \%)$ \\
Psoriasis & $50(2.52 \%)$ \\
Dystrophic nail & $36(1.81 \%)$ \\
Vitiligo & $35(1.76 \%)$ \\
Molluscum contagiosum & $34(1.71 \%)$ \\
Pityriasis alba & $34(1.71 \%)$ \\
Alopecia areata & $33(1.66 \%)$ \\
Benign melanocytic nevi & $31(1.56 \%)$ \\
\hline
\end{tabular}

TABLE 2. Distribution of main dermatoses among age groups

\begin{tabular}{lccccc}
\hline & \multicolumn{5}{c}{ Age groups n (\%) } \\
\hline & $\mathbf{n}$ & $\mathbf{0 - 1}$ & $\mathbf{2 - 5}$ & $\mathbf{6 - 1 1}$ & $\mathbf{1 2 - 1 7}$ \\
\hline Total & 1984 & $56(2.82 \%)$ & $362(18.24 \%)$ & $538(27.12 \%)$ & $1028(51.82 \%)$ \\
Male & 958 & $34(3.55 \%)$ & $198(20.67 \%)$ & $274(28.60 \%)$ & $452(47.18 \%)$ \\
Female & 1026 & $22(2.14 \%)$ & $164(15.98 \%)$ & $264(25.73 \%)$ & $576(56.14 \%)$ \\
\hline Dermatoses & $\mathbf{n}(\%)$ & & & \\
\hline Acne and follicular diseases & $395(19.91 \%)$ & $6(10.71 \%)$ & $5(1.38 \%)$ & $13(2.42 \%)$ & $371(36.09 \%)$ \\
Allergic skin diseases & $287(14.46 \%)$ & $14(25.00 \%)$ & $139(38.40 \%)$ & $80(14.87 \%)$ & $54(5.25 \%)$ \\
Eczemas & $219(11.04 \%)$ & $11(19.64 \%)$ & $40(11.05 \%)$ & $68(12.64 \%)$ & $100(9.73 \%)$ \\
Infectious diseases & $553(27.87 \%)$ & $4(7.14 \%)$ & $100(27.62 \%)$ & $238(44.24 \%)$ & $211(20.52 \%)$ \\
Papulosquamous diseases & $86(4.33 \%)$ & $0(0.00 \%)$ & $9(2.49 \%)$ & $34(6.32 \%)$ & $43(4.18 \%)$ \\
Genodermatoses & $22(1.11 \%)$ & $3(5.36 \%)$ & $3(0.83 \%)$ & $8(1.48 \%)$ & $7(0.68 \%)$ \\
Nevi and benign skin tumors & $87(4.18 \%)$ & $6(10.71 \%)$ & $14(3.87 \%)$ & $21(3.53 \%)$ & $47(4.57 \%)$ \\
Disorders of pigmentation & $56(2.82 \%)$ & $3(5.36 \%)$ & $8(2.21 \%)$ & $19(3.53 \%)$ & $26(2.53 \%)$ \\
Hair and nail diseases & $120(0.60 \%)$ & $4(7.14 \%)$ & $18(4.97 \%)$ & $16(2.97 \%)$ & $82(7.98 \%)$ \\
Others & $159(\%)$ & $5(8.93 \%)$ & $26(7.18 \%)$ & $41(7.62 \%)$ & $87(8.46 \%)$ \\
\hline
\end{tabular}


TABLE 4 . The diagnosis of patients in whom histopathology is required

\begin{tabular}{|c|c|c|c|}
\hline Diagnosis & $\begin{array}{l}\text { number of patients } \\
\text { n total= 103) }(5.2 \%)\end{array}$ & Diagnosis & $\begin{array}{l}\text { number of patients } \\
(\mathrm{n} \text { total }=103)(5.2 \%)\end{array}$ \\
\hline Psoriasis & 13 & Lichen striatus & 1 \\
\hline \multirow{2}{*}{$\begin{array}{l}\text { Urticaria } \\
\text { pigmentosa/mastocytosis }\end{array}$} & \multirow[t]{2}{*}{6} & Seborrheic dermatitis & 1 \\
\hline & & Mycosis fungoides & 1 \\
\hline Localized scleroderma & \multirow{2}{*}{$\begin{array}{l}5 \\
5\end{array}$} & Tinea corporis & 1 \\
\hline Pityriasis rubra pilaris & & Pernio & 1 \\
\hline Atopic dermatitis & 5 & Pyogenic granuloma & 1 \\
\hline Pityriasis rosea & 4 & Linear IgA bullous dermatosis & 1 \\
\hline Vitiligo & 4 & Erythema annulare centrifugum & 1 \\
\hline Benign melanocytic nevus & 4 & Pigmented purpuric dermatosis & 1 \\
\hline Lichen planus & 3 & Juvenile xanthagranuloma & 1 \\
\hline Sebaseous nevus & 3 & Lymphangioma & 1 \\
\hline Insect bite & 3 & Spitz nevus & 1 \\
\hline Leucocytoclastic vasculitis & 3 & Nevus lipomatosis superficialis & 1 \\
\hline Lichen sclerosis & 2 & Glandular cheilitis & 1 \\
\hline Epidermolysis bullosa & 2 & Cicatricial alopecia & 1 \\
\hline Erythema multiforme & 2 & Acute generalized erythematous & 1 \\
\hline Granuloma annulare & 2 & pustulosis & \\
\hline Drug eruption & 2 & Erythema nodosum & 1 \\
\hline Ashy dermatosis & 2 & Verrucous epidermal nevus & 1 \\
\hline Urticaria & 2 & Angiokeratoma corporis diffusum & 1 \\
\hline Becker nevus & 1 & Pilomatricoma & 1 \\
\hline Postinflammatory hypopigmentation & 1 & Compound nevus & 1 \\
\hline Pityriasis lichenoides et varioliformis acuta & ata & Lingual frenulum & 1 \\
\hline Pityriasis lichenoides chronica & 1 & Eruptive vellus hair cysts & 1 \\
\hline Lichen simplex chronicus & 1 & Polimorphic light eruption & 1 \\
\hline Ichthyosis vulgaris & 1 & & \\
\hline Lichen niditus & 1 & & \\
\hline
\end{tabular}

TABLE 5. The diagnosis of patients in whom phototherapy was required

\begin{tabular}{lc}
\hline Diagnosis & $\begin{array}{c}\text { number of patients } \\
\text { n total= }\end{array}$ \\
\hline Psoriasis & $11.3 \%)$ \\
Vitiligo & 7 \\
Localized scleroderma & 2 \\
Atopic dermatitis & 2 \\
Pityriasis rosea & 2 \\
Lichen planus & 1 \\
Pityriasis lichenoides chronica & 1 \\
Mycosis fungoides & 1 \\
\hline
\end{tabular}

received tap water iontophoresis. Fifteen $(0.76 \%)$ patients all girls and more than 16 (only one with localized hypertrichosis was 6 year aged) underwent laser hair removal. Laser treatment of vascular lesions (spider angioma) were done in $2(0.10 \%)$ patients. In $93(4.69 \%)$ patients no treatment is required. Six $(0.30 \%)$ of patients required surgical interventions.

\section{DISCUSSION}

The establishment of PD as a specialty is rather a recent activity with about 30 years background in U.S. and Europe. Whereas in our country, efforts of the Turkish Society of PD to adopt PD as a subspecialty is still going on, the official legislation is not provided, yet. By the year 2012, the Turkish children between 0-17 comprise 30\% of the total population. ${ }^{1}$ Although dermatology and pediatrics residency programmes cover the main topics of PD, the specialists on PD will probably fullfill an important gap.

The epidemiologic studies worldwide in the field of PD are limited. Geographical, environmental and socioeconomical factors may alter the frequencies of diseases in pediatric 
population. In many western studies, ${ }^{2-4}$ atopic dermatitis was found to be most common dermatoses whereas studies from developing countries usually demonstrate infectious diseases as the most common..$^{5-7}$ Our study also found infectious diseases as the most common dermatoses and among the infectious diseases the frequency of viral warts were prominent with a clear cut edge.

Viral warts are common in children worldwide and in our study it was the second most prevalent disease. Many western epidemiologic studies on pediatric skin diseases among PD clinic referrals found viral warts as the most common infectious diseases. ${ }^{3,8-10}$ In our study warts were especially common in school age children and adolescents. In a Dutch study, ${ }^{11}$ carried among children of school age the prevalence of cutaneous warts was found to be $29 \%$, and a similar British study found the prevalence rate as $33 \% .{ }^{12}$ A recent study in our country performed in primary school children, revealed a prevalence of $10.9 \% .{ }^{13}$ Preventive measures for HPV transmission gains importance. There are few reports of effectiveness of quadrivalent HPV vaccine on refractory cutaneous warts. ${ }^{14,15}$ In the future, routine vaccination of children for HPV may have beneficial effects. The high number of warty patients attending to our clinic may also reflect patients knowledge about role of cryotherapy in treatment of warts. Although spontaneous regression is possible in warts, a treatment modality is always offered in our clinic, and nearly two thirds of patients were treated with cryosurgery.

Viral exanthemas, pediculosis, parasitic diseases which are commonly encountered in general practice or pediatrics practice, were rare among our referrals. Furthermore, the common infectious diseases as impetigo that usually indicate the low socioeconomic status and poor hygiene status were relatively rare. But, since raising livestock and agriculture are the mainstay in rural area, dermatophyte infections were found to be common as well as insect bites.

Acne was the most common disease in our study, attributed to the high adolescent population in our study. Namely, it is a limitation for the study thus more than half of the study population is over 12. It also reflects the situation over the country. The neonatal and preschool age patients usually admit to clinics of pediatrics and dermatologists encounter these patients only in case of a referral. Both specialities have some superiority on the other so that a collaborative work must be carried out and the recognition and referral of the cases that are outside one's expertise is an important issue.

Atopic dermatitis was the third most common regarding all age groups but were the commonest disease among infants and preschool age children. Many western studies found atopic dermatitis as the most common disease ${ }^{2,3}$ but the high adolescent population in our study group probably peaked acne and warts.

Contact dermatitis in children was previously underrecognized but nowadays agreed as a common condition. ${ }^{16}$ It was the fourth most common dermatoses in our study. It is not always possible to perform patch testing to all individuals. Besides the positive patch test results in children can often be conflicting as false postive reactions may occur with the unstandardized hapten concentrations for children. Urticaria/ angioedema was also among the most common dermatoses similar to previous studies.

Psoriasis was again among the top ten dermatosis in children, with a $2.52 \%$ incidence among PD admissions. This is parallel with previous studies ${ }^{3,4}$ but actually one third of psoriasis patients are said to be at pediatric age group, ${ }^{17}$ thus a higher number was expected. Other common autoimmune skin diseases like alopecia areata $(1.66 \%)$ and vitiligo $(1.76 \%)$ have literature compatible results. ${ }^{18}$

The histopathology in skin diseases is an essential complementary part of the diagnosis. On the other hand, it is not commonly applied in diseases other than inflammatory or tumoral lesions in pediatric population. Although clinical diagnosis for psoriasis is frequently, biopsy can be mandatory sometimes just to relieve parent's concern. Not only psoriasis but other papulosquamous diseases in the differential diagnosis of psoriasis may require histopathological confirmation. The second most common dermatosis in which biopsy performed was cutaneous mastocytosis which usually has a benign course in children but follow-up is required since systemic involvement is possible in about $30 \%$ of the cases. ${ }^{19}$ In our clinic all patients suspected of mastocytosis undergo histopathological examination. On the other hand, tumoral or cystic lesions and sometimes nevi with suspicious dermoscopy usually require histopathological confirmation. In a previous study by Wenk and Itin, ${ }^{3}$ biopsy was performed in $1.7 \%$ of the cases which is much more lower 
than our rates (5.2\%). Patients finally admitting to a PD outpatient clinic of a university hospital are full of expectations and some of the biopsies performed may be to relieve the parents concerns.

When the preferred treatment modalities are considered, the low number of patients without any treatment also support the above mentioned situation on parents concern. Doctor shopping is common in childrens' diseases and this may be a common reason of preferring to give a treatment. Wenk and Itin $^{3}$ reported in their study, $66.0 \%$ of patients were given local treatments, $27.6 \%$ had no treatment and $18.6 \%$ were administered systemic treatments. On the other hand, the severity of diseases determine treatment options. In our study $2.2 \%$ of patients treated by immunosuppressive drugs, and systemic corticosteroids were the preferred agents. Iontophoresis and laser procedures are routinely available in our clinic and the high number of patients of localized hyperhidrosis and constitutional hirsutism which were not mentioned in previous studies may be attributed to this.

The congenital vascular and melanocytic lesions were relatively low in number. This makes us think that pediatricians should be informed, may be by in service training about the recent data on these conditons, as well as the public instructions for the conditions should be prepared.

In addition to retrospective nature, one of the limitations of our study may be the age limit, which is not obviously defined and varies in many other studies..$^{2-10}$ In fact, the patterns between different age groups varies prominently thus in the future, the pediatric dermatology may be further divided into neonatal dermatology, pediatric dermatology and adolescent dermatology.

This study is performed not only to demonstrate the distribution of various dermatoses among pediatric population but also to reveal the frequency of the diagnostic tests used and preferred treatment modalities.

\section{CONCLUSION}

Epidemiological studies on pediatric skin diseases are valuable to plan for preventive measures for the common dermatoses. Similar to many other studies, viral warts were among the common dermatoses in our study. Preventive studies for HPV transmission should become important part of the public health efforts in children.

\section{REFERENCES}

1. Address Based Population Registration System (ABPRS) Results 2013 [Internet]. Ankara: Turkish Statistical Institute. Available at: http://www.turkstat.gov.tr/ PreIstatistikTablo.do?istab_id=943. [Accessed on: April 16, 2014].

2. Schachner L, Ling NS, Press S. A statistical analysis of a pediatric dermatology clinic. Pediatr Dermatol 1983;1(2):15764.

3. Wenk C, Itin PH. Epidemiology of pediatric dermatology and allergology in the region of Aargau, Switzerland. Pediatr Dermatol 2003;20(6):482-7.

4. Can B, Kavala M, Türkoglu Z, Zindanci I, et al. Prevalence of skin conditions among pediatric patients in the region of Istanbul. Türkderm 2011;45(1):10-3.

5. Bilgili SG, Calka O, Akdeniz N, Karadag AS, Akbayram S. The prevalence of pediatric skin diseases in eastern Turkey. Int J Dermatol 2014;53(1):e6-e9.

6. Karthikeyan K, Thappa DM, Jeevankumar B. Pattern of pediatric dermatoses in a referral center in South India. Indian Pediatr 2004;41(4):373-7.

7. El-Khateeb EA. The spectrum of paediatric dermatoses in a university hospital in Cairo, Egypt. J Eur Acad Dermatol Venereol 2011;25(6):666-72.

8. Casanova JM, Sanmartín V, Soria X, Baradad M, et al. Dermatosis infantiles en la consulta de Dermatología de un hospital general universitario en España. Actas Dermosifiliogr 2008;99(2):111-8.

9. Ferreira FR, Nascimento LF, Cirvidiu DC. Prevalence of pediatric dermatoses in a university hospital in southeastern Brazil. An Bras Dermatol 2011;86(3):477-82.

10. Del Pozzo-Magana BR, Lazo-Langner A, GutierrezCastrellon P, Ruiz-Maldonado R. Common dermatoses in children referred to a specialized pediatric dermatology service in Mexico: A comparative study between two decades. ISRN Dermatol 2012;2012:351603.

11. Bruggink SC, Eekhof JA, Egberts PF, van Blijswijk SC, et al. Warts transmitted in families and schools: a prospective cohort. Pediatrics 2013;131(5):928-34.

12. van Haalen FM, Bruggink SC, Gussekloo J, Assendelft WJ, Eekhof JA. Warts in primary school children: prevalence and relation with environmental factors. $\mathrm{Br} J$ Dermatol 2009;161(1):148-52.

13. Çarman KB, Saglam H, Çarman E, Ekici A, Arslanta D. Prevalence of wart in a group of school children in Eski ehir. Turkiye Klinikleri J Pediatr 2013;22(2):66-9.

14. Daniel BS, Murrell DF. Complete resolution of chronic multiple verruca vulgaris treated with quadrivalent human papillomavirus vaccine. JAMA Dermatol 2013;149(3):370-2.

15. Landis MN, Lookingbill DP, Sluzevich JC. Recalcitrant plantar warts treated with recombinant quadrivalent human papillomavirus vaccine. J Am Acad Dermatol 2012; 67(2):e73-4.

16. Pigatto P, Martelli A, Marsili C, Fiocchi A. Contact dermatitis in children. Ital J Pediatr 2010;13(1):36:2.

17. RaychaudhuriSP, Gross J. A comparative study of pediatric onset psoriasis with adult onset psoriasis. Pediatr Dermatol 2000;17(3):174-8.

18. Kane KSM, Lio PA, Stratigos AJ, Johnson RA. Color atlas and synopsis of pediatric dermatology. 2nd ed. New York: Mc Graw-Hill Medical, 2009: 213,334.

19. Valent $P$, Aberer E, Beham-Schmid C, Fellinger C, et al. Guidelines and diagnostic algorithm for patients with suspected systemic mastocytosis: a proposal of the Austrian competence network (AUCNM). Am J Blood Res 2013;3(2):174-80. 